\title{
Diversidade não é igual à pluralidade - Proposta de categorização das fontes no radiojornalismo ${ }^{1}$
}

\author{
Marcelo Kischinhevsky \\ Luãn Chagas
}

Resumo: A partir de estudo exploratório, que tem como corpus 25 horas de programação da rádio BandNews FM do Rio de Janeiro, propõe-se uma nova categorização de fontes jornalísticas. No percurso, discute-se a diferença entre os conceitos de diversidade e pluralidade, considerados basilares para o jornalismo e para a própria noção de democracia, num contexto de crescente precarização das condições de trabalho e da imposição de um perfil multitarefa aos jornalistas de rádio. Os dados expõem uma série de condicionantes na busca do ideal de diversificação das vozes no dial e a prevalência de fontes cada vez mais profissionalizadas.

Palavras-Chave: jornalismo; rádio; fontes; diversidade; pluralidade.

\section{Abstract: Diversity is not equal to plurality - A proposal for categorization of sources in radiojournalism - From an exploratory study which delimited as a corpus 25 hours of programming of Rio de Janeiro radio station BandNews FM, a new categorization of journalistic sources is proposed. Along the way, we discuss the difference between the concepts of diversity and plurality, considered basilar to journalism and to the very notion of democracy, in a context of increasingly precarious working conditions and the multi-tasking profile imposed to radio journalists. The data expose a series of constraints in the search for the ideal of diversification of voices on the dial and the prevalence of increasingly professional sources.}

Keywords: journalism; radio; sources; diversity; plurality.

\section{Introdução}

Ao longo dos últimos dois séculos, o jornalismo ganhou institucionalidade, assumindo-se como locus da promoção e da preservação da diversidade e da pluralidade,

1 Versão de trabalho apresentado durante o XXVI Encontro Anual da Compós, realizado em São Paulo (SP), em junho de 2017. Os autores agradecem à Faperj e ao CNPq pelo apoio às suas pesquisas. 
ao estabelecer uma agenda pública de debates, ao atuar como fiscal dos poderes constituídos e também ao oferecer conteúdos informativos que supostamente contemplam a multiplicidade de vozes na sociedade. Ao fazer um histórico das ideias de pluralidade e diversidade, imbricadas com a própria noção de democracia - remetendo a pensadores como Tocqueville e Mill -, Canela e Siqueira (2011) assinalam que valores como direito de manifestação, proteção dos direitos humanos das minorias e liberdade de expressão se tornaram chaves na construção das democracias contemporâneas. "Quanto mais abrangente e qualificada for a garantia do direito humano à liberdade de expressão (falar, buscar e disseminar), mais diversas e plurais serão as sociedades" (CANELA; SIQUEIRA, 2011, p. 84-85).

Nas últimas décadas, esse papel de guardião da diversidade e da pluralidade passou a ser estendido à mídia em geral. Nesse sentido, resumem os autores, a mídia só poderia promover e garantir a diversidade e a pluralidade cultural e social se ela mesma for plural e diversificada. Em 2006, contudo, de acordo com a Organização das Nações Unidas para a Educação, a Ciência e a Cultura (Unesco), 11 corporações dominavam a produção mundial de conteúdo. No Brasil, coincidentemente, 11 famílias comandavam mais de $60 \%$ das concessões de rádio e televisão no mesmo período (LIMA, 2006).

Nesse contexto, a preocupação de organismos internacionais com diversidade e pluralidade tem se intensificado nos últimos anos. Em 2008, o Programa Internacional para o Desenvolvimento da Comunicação da Unesco publicou Indicadores de Desenvolvimento da Mídia, ferramenta de avaliação dos sistemas midiáticos nacionais, abarcando cinco grandes categorias:

- Um sistema regulatório favorável à liberdade de expressão, ao pluralismo e à diversidade da mídia;

- Pluralidade e diversidade da mídia, igualdade de condições no plano econômico e transparência da propriedade;

- A mídia como plataforma para o discurso democrático;

- Capacitação profissional e instituições de apoio à liberdade de expressão, ao pluralismo e à diversidade;

- Infraestrutura suficiente para sustentar uma mídia independente e pluralista.

Como se pode perceber, pluralidade e diversidade tornaram-se valores ambicionados em nível internacional, mas geralmente são dados como sinônimos e tratados como conceitos auto-evidentes (KISCHINHEVSKY, 2013). Entende-se aqui que são ideias interconectadas, embora guardem diferenças significativas: num ecossistema midiático cada vez mais complexo, não basta haver um grande número de meios de comunicação, se a maioria pertence a um seleto clube de grandes empresas. O mesmo se dá, por exemplo, na construção do fluxo de programação de meios eletrônicos. Embora dezenas de fontes jornalísticas sejam acionadas num dia típico por uma emissora de rádio do segmento All News (só notícias), o que poderia ser entendido como pluralidade de vozes, não há diversidade entre elas se a maioria fala de um mesmo lugar. 
Ambos os conceitos são objeto de incontáveis discussões sobre teoria política da democracia², esfera pública e comunicação massiva (McQUAIL, 2003). Thompson (2000) advoga o que ele chama de pluralismo regulado dos meios de comunicação social, em que os espaços franqueados na programação dos meios a organizações da sociedade civil, como sindicatos, movimentos sociais, universidades e centros de pesquisa, desempenhariam papel-chave na oferta de bens simbólicos. Van Cuilenburg (1999), por sua vez, conceitua a diversidade midiática como modo de garantir a heterogeneidade de conteúdo com características específicas. Já para Morais (2012), fatores como a abundância de informações e o surgimento de novos atores e meios de comunicação levam a uma separação entre os conceitos de diversidade e pluralidade.

A diversidade de vozes é preconizada por teóricos do jornalismo como critério para assegurar qualidade em uma cobertura informativa. Nessa direção, a legislação brasileira prevê regulação estatal do espectro e a concessão de frequências de radiodifusão a empresários que deveriam garantir a pluralidade e a diversidade de temas e vozes, observando preceitos éticos e finalidades educativas, artísticas, culturais e informativas (BRASIL, 1988). Percebe-se, contudo, clara omissão do poder público na regulação das atividades jornalísticas, sempre denunciada como tentativa de censura por entidades empresariais do setor.

O objetivo deste artigo vai ao encontro da discussão que diferencia pluralidade de diversidade e busca investigar como essas se inserem nas rotinas jornalísticas do rádio. Para isso, a profissionalização e classificação das fontes nas teorias do jornalismo e o processo de seleção específico do radiojornalismo demonstram as amplas possibilidades destinadas aos profissionais no momento da seleção e apuração.

O estudo, de caráter exploratório, faz parte de tese de doutoramento do segundo autor, com orientação do primeiro. Visa auxiliar a classificação inicial das fontes que busca amparar o entendimento dos mecanismos de construção da notícia no rádio, com reflexões sobre as práticas de coleta e apuração de informações.

\section{Fontes no jornalismo e as especificidades no radiojornalismo}

Os critérios de seleção jornalística, com os diferentes valores-notícia para os acontecimentos, enquadram um aspecto decisivo no tratamento dos fatos: a escolha das fontes. Quem diz, como diz e seus respectivos locais de fala estão presentes em grande parte da literatura relativa às teorias do jornalismo. Neste ponto, a pluralidade e a diversidade de fontes e sua participação na construção da notícia levantam discussões para além de aspectos normativos ou éticos da comunidade interpretativa.

2 Teóricos clássicos do pluralismo como John Rawls, Stuart Mill e Alexis Tocqueville posicionam o debate no centro da sustentação das liberdades individuais e na própria construção da democracia. Tocqueville chega a correlacionar o pluralismo na imprensa e o pluralismo na vida democrática. Habermas, na concepção sobre sociedade civil na esfera pública, debate com Rawls as condições do pluralismo na democracia qualificada. Recentemente, Margetts, John, Hale e Yasseri (2016) revisitaram os autores em uma análise sobre as mídias sociais e formularam o conceito de pluralismo caótico para tentar dar conta das turbulências políticas da atualidade. 
No âmbito profissional, de produções cada vez mais ligeiras realizadas por repórteres incumbidos de múltiplas tarefas, Becker (2012) destaca que o imediatismo e a instantaneidade presentes na realidade da cobertura jornalística nem sempre colaboram para a formação de consciências críticas para superar determinadas realidades históricas, para assim promover a diversidade. Segundo a pesquisadora, mesmo com a ampliação de participação com as novas tecnologias, ainda falta uma exploração inventiva da linguagem que leve à possibilidade de diversificação e pluralidade.

Outro aspecto é a falta de demarcações claras entre o jornalismo e a assessoria de imprensa ou entre informação e entretenimento. Além disso, argumenta Becker (2011), a falta de reportagens contextualizadas que expressem a diversidade de vozes é resultado de novos modos de construção da notícia que podem ser influenciados por atores alheios ao interesse público. A atuação do profissional torna-se resumida, com as novas formas de seleção, à chamada curadoria (curation) ou à atuação como gatewatcher (BRUNS, 2005), em função das possibilidades de interação com o público. Cada vez mais, o jornalista reescreve ou filtra conteúdos informativos enviados por fontes profissionalizadas, públicas ou privadas, em vez de apurar, de ir a campo em busca dos fatos.

Para Karam (2004), a discussão sobre a pluralidade de versões é uma das bases do jornalismo como parte do espaço público presente na discussão sobre a relação ética ao tratar os acontecimentos. No caso do radiojornalismo, o ideal de diversidade e pluralidade permeia discussões sobre a legislação ou a regulação do espectro de radiofrequência, como nos estudos de Moreira (1998) e Chagas (2012), que explicitam os casuísmos e os interesses políticos e econômicos contemplados na distribuição de concessões de rádio no Brasil ao longo da história.

O processo de seleção de fontes e a transparência da origem das informações veiculadas pelos suportes informativos são discussões constantes nas reflexões em torno da construção da notícia. Saber de onde vêm as notícias não é somente uma questão retórica, mas um fator decisivo para a manutenção do jornalismo como instituição social e parte do conjunto de interesses públicos em uma sociedade democrática. Classificar as fontes no radiojornalismo possibilita cartografar diferenças de posição, de interesse, de ação política, participação e acesso ao temário jornalístico.

Esse exercício é também um esforço de enxergar quais relações estão em disputa na mediação destes sentidos. A classificação demonstra a infinidade de formas de encontrar e posicionar as diferentes vozes, porém leva a outros questionamentos, como a preponderância na escolha de fontes oficiais (SCHLESINGER, 1992). Na ótica de Hall et al. (1999), há diferenças de abordagens entre fontes primárias e secundárias na produção de sentido. De acordo com os autores, as rotinas produtivas permeadas pelas pressões por rapidez na produção e exigências profissionais de objetividade levam a um acesso sistemático por parte dos definidores primários - instituições e atores com papéis privilegiados econômica e politicamente. 
Para compreender as diferentes disputas de sentido, torna-se fundamental enxergar as fontes a partir de seu protagonismo na promoção dos acontecimentos, como abordam Molotch e Lester (1999). Para os autores, a diferença de status e relações de poder entre as fontes se dá por três formas: a) quando os promotores têm acesso habitual à mídia, como é o caso de fontes oficiais, sobretudo altos funcionários do governo; b) acesso disruptivo, quando os acontecimentos promovidos se tornam um problema para os poderosos em manifestações, ocupações e outras atividades das fontes; c) acesso direto com a investigação de dados promovida pelos jornalistas com a criação de novas ocorrências (MOLOTCH e LESTER, 1999).

Um dos primeiros a classificar as fontes por tipos, Gans (1980) propõe a divisão entre fontes institucionais, oficiais, oficiosas, provisórias, passivas, ativas, conhecidas e desconhecidas, argumentando que os agentes selecionados nas notícias representam suas posições na estrutura social. Wolf (2009) defende que as fontes podem ser centrais, territoriais e de base, divididas pela localização espacial, mas também a partir da relação com os critérios de noticiabilidade utilizados em sua seleção. O autor segue a linha de Borrat (1981) na separação entre fontes ativas e passivas e seu nível de utilização. Essa definição tem por objetivo categorizá-las não somente pelo tipo que representam, mas compreender que a seleção e a articulação destas vozes no noticiário não é casual ou arbitrária. Assim, jornalistas e fontes coexistem dentro de um sistema que revela exercícios de poder e disputas entre os agentes pela interpretação da realidade.

De acordo com Erbolato (2008), as fontes podem ser divididas entre fixas, como aquelas que os jornalistas acessam em sua agenda diária e com as quais mantêm relação próxima; e as fora de rotina, que são procuradas em determinados eventos, de forma excepcional. Por fim, o autor ainda as divide em diretas - pessoas envolvidas com determinados fatos, notas, comunicados, livros, almanaques -, indiretas e adicionais.

Lage (2001, p. 65), por sua vez, organiza as fontes de natureza mais ou menos confiável: pessoais, institucionais, documentais ou então oficiais, oficiosas e independentes, ou ainda primárias (eixo da reportagem) e secundárias (empregadas na pré-apuração ou na elaboração de pautas).

Schimitz (2011, p. 9) argumenta que é necessário diferenciar fontes de informação e de notícia. Enquanto qualquer informação está disponível a alguém, a relacionada à notícia precisa de um mediador que faça ou promova a circulação de seu conhecimento, seu saber ou testemunho. Segundo o autor, elas podem ser divididas da seguinte forma: oficiais (alguém em função de um cargo público); empresariais (representante de uma corporação da indústria, comércio, serviços ou agronegócio); institucionais (representantes de organizações sem fins lucrativos); populares (pessoas comuns); notáveis (selecionadas por talento ou fama); testemunhais (observadores ou participantes de um acontecimento); especializadas (de notório saber técnico-científico); referência (bibliografia, documento ou mídia que serve de suporte) (SCHIMITZ, 2011, p. 26-27). 
Com o que chama de revolução das fontes, Chaparro (1994) destaca a profissionalização dos sujeitos, agora institucionalizados, que se capacitam para produzir acontecimentos, que geram conteúdos e, assim, interferem na pauta jornalística. Sant'anna (2009) avança no sentido de mapear como as mídias das fontes exercem o papel duplo de sensibilizar a pauta de jornais, emissoras de rádio e televisão e o próprio público que cultivam, indicando que, cada vez mais, organizações públicas ou privadas investem na comunicação direta com seus públicos de interesse e fornecem grande volume de informação para amparar a construção do noticiário, direta ou indiretamente. Neste sentido, a internet agrega um conjunto de estratégias e oferece manancial de fontes para os jornalistas, promovendo alterações em sua natureza e no próprio sistema de produção (MACHADO, 2003).

Nos estudos de radiojornalismo, numa fase caracterizada pela multiplicidade da oferta de conteúdos (BRITTOS, 2002), Ferraretto (2014) propõe uma classificação de fontes a partir de duas modalidades: internas e externas. As internas compreendem as equipes de reportagem, enviados especiais, editores, correspondentes, apuração dentro da redação. Já as externas abrangem assessorias de imprensa, agências de notícias, informantes e internet. Porém, como afirma Lopez (2010), fontes internas e externas estão fortemente imbricadas, com um fluxo informativo cada vez mais veloz e profissionalizado entre as fontes oficiais e os jornalistas nas redações. Ao analisar as novas configurações de formatos no chamado rádio hipermidiático, Lopez (2010, p. 76) identifica as fontes em três níveis: a) primário consultadas em campo; b) secundário - agentes que analisam os acontecimentos; c) terciário - quando as informações chegam às redações por outros meios de comunicação, assessorias e agências. Lopez também argumenta que a participação do ouvinte fornecendo informações sobre o cotidiano das cidades vai além da audiência e passou do telefone para a internet.

Rutilli (2014) vai na mesma direção e sustenta que é necessário olhar para as fontes que passaram a se apropriar de ferramentas no ambiente digital para a conquista de lugares de fala, além da própria busca de fontes e personagens pelos jornalistas nas redes sociais online. A pesquisadora menciona fontes convergentes, que se organizariam em torno de aplicativos, possibilitando o crowdsourcing por parte das emissoras de rádio caso de WhatsApp e Waze. Entende-se aqui, contudo, que estes aplicativos constituem apenas novos filtros moderadores para a participação do público no noticiário, em áreas específicas de cobertura como trânsito e crimes, e não fontes em si.

Com base na revisão acima, propõe-se a seguinte categorização de fontes:

- Oficiais - Ocupantes de cargos eletivos e funcionários do Executivo, do Legislativo, do Judiciário e do Ministério Público, de autarquias, fundações e empresas públicas, em níveis federal, estadual e municipal;

- Empresariais - Associações representativas dos setores comercial, financeiro, industrial, agronegócio, de serviços, corporações, consultorias, executivos;

- Institucionais - Integrantes de organizações do terceiro setor, organismos 
multilaterais, movimentos sociais, organizações sindicais;

- Testemunhais - Personagens que presenciaram acontecimentos com valor-notícia atribuído por jornalistas e radialistas;

- Populares - Pessoas comuns, que em geral são representadas no noticiário como vítimas de determinada situação - um crime, uma injustiça, uma política pública ineficiente - ou lançam mão de táticas de espetacularização para se fazer ouvir e reivindicar melhorias no seu cotidiano;

- $\quad$ Especialistas - Profissionais com reconhecido saber técnico ou científico sobre determinado campo em torno do qual se desenvolve uma cobertura jornalística;

- Notáveis - Celebridades, artistas, esportistas, comunicadores, pessoas que desempenham ou desempenharam atividades de grande reconhecimento social, sobre as quais se atribuem variáveis valores-notícia.

Jornalistas figuram na esfera da produção e não constituem fontes de notícias, exceto quanto algo sai do script e estes as protagonizam - caso de repórteres que são vítimas de agressões ou acidentes no exercício da profissão, por exemplo. Outros meios de comunicação são acompanhados, mas, salvo em furos de reportagem (cada vez mais esporádicos), não constituem fontes em si: sempre estarão referenciando um dos tipos citados acima.

\section{Estudo de caso: as fontes na BandNews FM}

A BandNews Rio é parte de uma rede sob o comando da família Saad no Brasil, que integra ainda negócios em TV aberta e fechada e internet. O formato da emissora é Talk and News, mas figura nas pesquisas do Kantar Ibope Media como a All News mais ouvida na cidade $^{3}$. A sede fica no Rio de Janeiro, embora a concessão originalmente seja de Niterói, na região metropolitana. É a segunda emissora mais importante da rede, fundada em 2004 na capital paulistana após a compra da então Rádio Sucesso, quando a BandNews se tornaria a primeira a transmitir notícias 24 horas por dia em FM no país. Em 2016, contava com cabeças de rede em São Paulo e Rio de Janeiro e afiliadas em Belo Horizonte, Porto Alegre, Salvador, Curitiba, Brasília, Fortaleza, João Pessoa, Vitória e Orlando, nos Estados Unidos, entre outras praças.

O crescimento do número de afiliadas e os números da audiência da rede, no entanto, não estão refletidos no quadro de jornalistas. No Rio, conta com uma redação de apenas 30 pessoas, entre profissionais e estagiários ${ }^{4}$, com as mais diversas atribuições, inclusive a operação da mesa de som no estúdio on air. A imposição de um perfil de profissional

3 Dado divulgado pela Associação de Emissoras do Rio de Janeiro (AERJ) em março de 2016, disponível em: http:// www.aerj.com.br/noticia/444-disputa-pelo-topo-segue-acirrada-no-rio-de-janeiro-jb-fm-e-super-radio-tupiavancam. Nos EUA, consultorias costumam analisar o segmento chamado News/Talk/Information, que abrange tanto rádios populares (Talk and News) quanto as emissoras de informação 24 horas por dia (All News). Daí a recente indistinção entre eles nas pesquisas do lbope. Até maio de 2017, a emissora era conhecida como BandNews Fluminense FM. A partir desta data, mudou de frequência, para $90,3 \mathrm{MHz}$, assumindo a atual denominação.

4 Informação fornecida pelo chefe de reportagem Mario Dias Ferreira, em visita à emissora, em 6/11/2016. 
multitarefa e multiplataforma é uma realidade presente no radiojornalismo, com equipes enxutas de jornalistas, cada vez mais confinados às redações, devido à política de redução de custos com deslocamentos.

As condições de trabalho do jornalista sentado e ausente do palco dos acontecimentos (NEVEU, 2006; PEREIRA, 2004; LOPEZ, 2010) fazem parte de um contexto de produção de um rádio expandido, que transborda para além do dial e está presente em múltiplos dispositivos e plataformas (KISCHINHEVSKY, 2016). Situação que condiciona o processo de produção jornalística e pode provocar um enfraquecimento da cobertura em aspectos como a seleção e a busca de diferentes fontes de informação para a construção da notícia. Juntamente com esse processo, a profissionalização das fontes e o surgimento de novos atores no mercado são partes de um processo de alargamento dos portões supostamente guardados pelos gatekeepers.

Considerando esses aspectos, o estudo de caso, de caráter exploratório, analisa o conjunto da produção jornalística da emissora durante 25 horas ao longo de uma semana, entre 21 e 25 de novembro de 2016. Foram priorizados os horários de pico de audiência, entre $6 \mathrm{~h}$ e $9 \mathrm{~h}$ e entre $18 \mathrm{~h}$ e $21 \mathrm{~h}$ de segunda, quarta e sexta-feira e das $9 \mathrm{~h}$ às $12 \mathrm{~h}$ de terça, quinta e sábado. Após a coleta, os dados foram divididos em categorias, levando-se em consideração a inter-relação entre jornalistas e fontes na construção da notícia (ALSINA, 2009) e as questões de espaço e tempo na rede informativa (TUCHMAN, 1983).

Ao longo da semana destacada, o estudo abrange os horários nobres do rádio em programas como Notícias da Manhã, BandNews Rio $1^{a}$ Edição e BandNews Rio $3^{a}$ Edição. Em todos, o formato Talk and News é a marca, com conversas entre os locutores - caso dos(as) âncoras Ricardo Boechat, Carla Bigatto e Rodolfo Schneider, pela manhã - e entradas (em geral, ao vivo) de comentaristas contribuindo para discussões específicas. Enquanto nas primeiras horas da manhã são posicionados comentaristas sobre tecnologia, mundo empresarial, viagem e esportes, nos demais horários, temáticas relacionadas ao hard news, como política e economia, têm uma concentração maior.

No primeiro movimento da análise, a distribuição quantitativa das fontes ao longo da programação revela as disparidades entre os grupos sociais nas disputas de sentido por determinadas temáticas. A ausência de diversidade, como mostra o gráfico abaixo, corrobora a prevalência das fontes oficiais. Ao todo, 223 fontes foram detectadas, sendo que $55 \%$ delas são oficiais, o que denota a preferência pelos agentes públicos em uma semana marcada pela renúncia do então ministro da cultura, Marcelo Calero, após denúncias contra o então secretário de governo, Geddel Vieira Lima, e pela queda de um helicóptero da polícia junto à Linha Amarela (mais importante via entre as zonas Norte e Oeste do Rio) em um dia de intensos tiroteios na comunidade vizinha da Cidade de Deus. Nesta categoria também foram inseridas as informações repassadas pelo Centro de Operações da Prefeitura do Rio. A participação do público via email, telefone, redes sociais ou aplicativos como WhatsApp possibilita a presença de $23 \%$ de vozes que se encaixam 
na tipologia popular. Os especialistas, que foram ouvidos ao longo de reportagens, entrevistas e outras abordagens analisadas adiante, foram $11 \%$. Por fim, aparecem testemunhas (4\%), fontes empresariais (4\%), notáveis (2\%) e institucionais (1\%).

A discussão sobre diversidade e pluralidade, num segundo movimento, permite aprofundar as discussões quantitativas, quanto à atividade desempenhada pelas fontes em cada um dos pontos abordados pelos enunciadores. As fontes oficiais ganharam destaque em cinco eixos temáticos recorrentes: política, segurança, ajuste fiscal, trânsito e investigação de casos de corrupção (sobretudo a Operação Lava Jato). Em política, dois deputados, o presidente da Câmara, Rodrigo Maia (DEM-RJ), e o relator de pacote de medidas contra a corrupção, Onix Lorenzoni (DEM-SC), foram os principais atores que discutiram o projeto do Ministério Público. Enquanto Maia falou sobre negociações e trâmites na Casa, Lorenzoni destacava as assinaturas ao projeto - posteriormente desfigurado no plenário - como apelo para a aprovação. Por fim, o Caso Geddel Vieira Lima foi abordado pelo ex-ministro Marcelo Calero e houve relatos de deputados contrários e favoráveis à investigação na Comissão de Ética Pública da Presidência da República. Quanto ao trânsito, a totalidade das informações partiu do Centro de Operações da Prefeitura, que reúne órgãos como Companhia de Engenharia de Tráfego (CET-Rio), Polícia Militar, Corpo de Bombeiros e Defesa Civil, oferecendo um fluxo amplo e constante de dados oficiais relativos à vida cotidiana na capital fluminense. A BandNews foi a primeira emissora a alocar setoristas no Centro de Operações, que hoje dispõe de sala de imprensa para abrigar repórteres de dezenas de veículos.

\section{Fontes BandNews Fluminense}

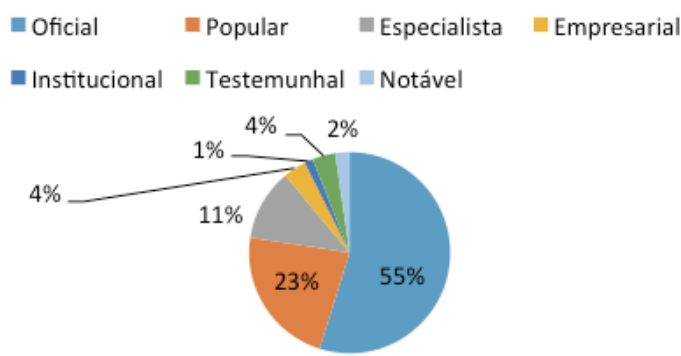

Fig.1. Fontes BandNews Fluminense. Fonte: 25h Programação BandNews FM de 21 a 25 de novembro

No caso da segurança, as fontes oficiais selecionadas para discutir a investigação da queda do helicóptero nos arredores da Cidade de Deus, que resultou na morte de quatro policiais no Rio de Janeiro, foram a Polícia Civil, o Ministério Público, a Unidade 
de Polícia Pacificadora da comunidade e a Aeronáutica. A Secretaria de Administração Penitenciária também figurou no corpus ao tratar da situação do ex-governador Sérgio Cabral Filho no complexo prisional de Bangu. Já em relação ao ajuste fiscal, registra-se uma preponderância das falas do presidente da Assembleia Legislativa do Rio de Janeiro (Alerj), Jorge Picciani, e dos governadores do Rio de Janeiro, Luiz Fernando Pezão, e do Rio Grande do Sul, Ivo Sartori, e do presidente do Banco Central, Henrique Meirelles. Por fim, a cobertura da Operação Lava Jato seguiu duas vozes preferenciais: integrantes da Justiça Federal de Curitiba e do Ministério Público Federal.

O segundo tipo de fonte mais utilizado pela programação foi o popular, o que não se traduz em um aprofundamento sobre temáticas como política ou ajuste fiscal do Estado. As participações via WhatsApp, telefone ou Facebook se restringiram às informações sobre condições de trânsito e casos voltados à segurança, como tiroteios ou roubos. Em apenas um caso, uma moradora da Cidade de Deus relata situações vivenciadas pela comunidade com a invasão de residências pela Polícia Militar.

Já os especialistas, na área política, comentaram sobre o Caso Geddel Vieira Lima e a decisão inicial do presidente Michel Temer de mantê-lo no cargo, sobre a votação das medidas contra a corrupção e, no sábado, sobre a repercussão internacional da morte do líder revolucionário cubano Fidel Castro. Em segurança, dois ex-comandantes da PM e do Batalhão de Operações Especiais (Bope) falaram sobre as ações na Cidade de Deus. Já na economia, questões como as reações do mercado financeiro ao noticiário político estiveram no foco dos jornalistas. Todos os especialistas acionados nas reportagens sobre o ajuste fiscal eram favoráveis às medidas de austeridade adotadas pelo governo do Rio de Janeiro (apelidadas pelos sindicatos de servidores de "pacote de maldades"), ou então à Proposta de Emenda Constitucional n 55 (chamada pela rádio de "PEC do teto de gastos", mas classificada por oposicionistas como "PEC do fim do mundo").

Quanto às fontes testemunhais, um policial relatou as condições de trabalho com os problemas salariais enfrentados no Estado, e o marido de uma mulher atingida por bala perdida dentro de casa falou sobre o ocorrido. Um advogado deu depoimento sobre os atrasos no andamento de processos com a greve de servidores do Tribunal de Justiça do estado do Rio de Janeiro. Na categoria empresarial, apenas as concessionárias das barcas e da Ponte Rio-Niterói foram acionadas no noticiário sobre as condições de tráfego. Identificam-se ainda publi-reportagens - novo formato de publicidade radiofônica - assinadas por empresas como Toyota e Dell.

A atriz Letícia Sabatella e o autor de um romance sobre violência foram ouvidos como fontes notáveis em entrevistas sobre arte e cultura, mas também política e violência. Por fim, um indicativo da ausência da sociedade civil organizada na programação é o fato de apenas a Ordem dos Advogados do Brasil (OAB-RJ) e a Comissão de Direitos Humanos de São Paulo serem ouvidas - respectivamente, sobre os problemas na Justiça do Rio de Janeiro e sobre a prisão de integrantes da comissão em operação da Polícia Civil paulista - nesta categoria. 
Assessoria de imprensa foi citada apenas uma vez, a partir de uma nota do Hospital Souza Aguiar, o que revela que as fontes profissionalizadas estão ao longo da programação, mas não citadas de forma direta, presentes a partir da apuração desempenhada internamente pelos jornalistas na redação.

\section{Considerações finais}

A análise preliminar aponta caminhos importantes para reflexão, a partir das teorias do jornalismo, sobre a ausência de um processo de seleção que privilegia a correlação de vozes sobre determinadas temáticas. A limitada diversidade de atores acionados como fontes possibilita repensar as lógicas de produção noticiosa no âmbito radiofônico, lançando nova luz sobre os mecanismos por trás do estabelecimento de uma agenda pública de debates sociais e de mobilização da audiência.

A categorização das fontes proposta fornece bases para pensar os estudos de jornalismo voltados às características radiofônicas. A seleção nas redações radiofônicas expõe uma estrutura de trabalho na qual a velocidade do fluxo informativo não delimita claramente situações que agrupem fontes internas ou externas, por exemplo. A profissionalização das fontes tem como objetivo sensibilizar e enviar informações aos jornalistas em um ritmo cada vez mais intenso. Já não é possível demarcar fronteiras entre materiais apurados somente por jornalistas e aqueles oriundos de fontes.

Não basta, portanto, que as reportagens ouçam mais de um entrevistado e envolvam participações por diferentes plataformas para responderem à expectativa de pluralidade e diversidade no jornalismo. A construção da notícia demanda a escuta de fontes que possam confrontar diferentes opiniões e assim fornecer informações que agreguem os diversos interesses particulares para a busca do interesse público. Isso pressupõe reconhecer a possibilidade de fontes populares que também interpretem os acontecimentos políticos, econômicos, de segurança pública, em toda a sua ressonância. Também é permitir que a interpretação e o comentário acerca do noticiário possam partir de pessoas que não representem somente o Estado, instituições, empresas ou especialistas, agregando setores da sociedade civil organizada e cidadãos comuns, capazes de relacionar seu cotidiano aos debates públicos que encontram lugar no jornalismo.

É necessário, em suma, garantir tanto a pluralidade de fontes, com uma representatividade dos atores sociais, quanto a diversidade, com a incorporação de outras vozes além daquelas identificadas com o poder público e os grupos políticos e econômicos mais organizados para assegurar acesso contínuo aos meios de comunicação.

Os dados apresentados levam a questões em aberto para o radiojornalismo, como a seleção específica das fontes e a importância destes agentes na construção da notícia - questões que serão abordadas em estudos futuros. 
Marcelo Kischinhevsky é professor do Departamento de Jornalismo e do Programa de Pós-Graduação em Comunicação da Faculdade de Comunicação Social da Universidade do Estado do Rio de Janeiro (FCS/UERJ), líder do Grupo de Pesquisa Mediações e Interações Radiofônicas.

marcelokisch@gmail.com

Luãn Chagas é doutorando do Programa de Pós-Graduação em Comunicação da Universidade do Estado do Rio de Janeiro (PPGCOM/UERJ) e integrante do Grupo de Pesquisa Mediações e Interações Radiofônicas.

luaanchagas@gmail.com

\section{Referências}

ALSINA, M. R. A construção da Notícia. Petrópolis, RJ: Vozes, 2009.

BECKER, B. Desafios da profissão, do ensino e da pesquisa em jornalismo. In: KISCHINHEVSKY, M.; IORIO, F. M.; VIEIRA, J. P. D. (org.). Horizontes do jornalismo: formação superior, perspectivas teóricas e novas práticas profissionais. Rio de Janeiro: E-papers, 2011.

. Jornalismo audiovisual de qualidade: um conceito em construção. In: BECKER, B.; TEIXEIRA, J.; MATEUS, L. (org.). Pensando e fazendo jornalismo audiovisual: a experiência do projeto TJ UFRJ. Rio de Janeiro: E-papers, 2012.

BORRAT, H. Once versiones noratlánticas del 23-F. Analisi: Quaderns de Comunicació i Cultura, n. 4, p. 91-113, 1981.

BRASIL. Constituição Federal da República Federativa do Brasil de 1988. Brasília: Presidência da República/Casa Civil, 1988.

BRITTOS, V. C. O rádio brasileiro na fase da multiplicidade da oferta. Verso \& Reverso. São Leopoldo: Universidade do Vale do Rio dos Sinos, ano 16, n. 35, p. 31-54, jul.-dez. 2002.

BRUNS, A. Gatewatching: collaborative online news production. New York: Peter Lang, 2005.

CANELA, G.; SIQUEIRA, A. B. de. Regulação para a pluralidade e a diversidade na mídia. In: BARROS, J. M.; KAUARK, G. (org.). Diversidade cultural e desigualdade de trocas - participação, comércio e comunicação. São Paulo: Itaú Cultural; Observatório da Diversidade Cultural. Editora PUC Minas, 2011.

CHAGAS, G. Radiodifusão no Brasil: poder, política, prestígio e influência. São Paulo: Ed. Atlas, 2012.

CHAPARRO, M. C. Pragmática do jornalismo: buscas práticas para uma teoria da ação jornalística. São Paulo: Summus Editorial, 1994.

ERBOLATO, M. L. Técnicas de codificação em jornalismo: redação, captação e edição no jornal diário. São Paulo: Ática, 2008.

FERRARETTO, L. A. Rádio - teoria e prática. 1. ed. São Paulo: Summus, 2014. 
GANS, H. J. Deciding what's news: a study of CBS Evening News, NBC Nightly News, Newsweek and Time. New York: Vintage, 1980.

HALL, S. et al. (1999). A produção social das notícias: o mugging nos mídia. In: TRAQUINA, Nelson (Org.). Jornalismo: questões, teorias e estórias. Lisboa: Vega, 1999.

KARAM, F. J. C. A ética jornalística e o interesse público. São Paulo: Summus, 2004.

KISCHINHEVSKY, M. Rádio e mídias sociais: mediações e interações radiofônicas em plataformas digitais de comunicação. Rio de Janeiro: Mauad X, 2016.

Por qual diversidade lutar? Desafíos à regulação no rádio musical brasileiro. In: DANTAS, Marcos; KISCHINHEVSKY, Marcelo (org.). Políticas públicas e pluralidade na comunicação e na cultura. Rio de Janeiro: E-Papers, 2013.

LAGE, N. A reportagem: teoria e técnica de entrevista e pesquisa jornalística. Rio de Janeiro: Record, 2001.

LIMA, V. A. de. Mídia: crise política e poder no Brasil. São Paulo: Fundação Perseu Abramo, 2006.

LOPEZ, D. C. Radiojornalismo hipermidiático: tendências e perspectivas do jornalismo de rádio all news brasileiro em um contexto de convergência tecnológica. Covilhã: UBI/LabCom Books, 2010.

MACHADO, E. O ciberespaço como fonte para os jornalistas. Salvador: Calandra, 2003.

MARGETTS, H.; JOHN, P.; HALE, S. A.; YASSERI, T. Political turbulence: how social media shape collective action. Princeton e Oxford: Princeton University Press, 2016.

McQUAIL, D. Teoria da Comunicação de Massas. Lisboa: Fundação Calouste Gulbenkian, 2003.

MOLOTCH, H. \& LESTER, M. A notícia como procedimento intencional: acerca do uso estratégico de acontecimentos de rotina, acidentes e escândalos. In: TRAQUINA, N. (Org.). Jornalismo: questões, teorias e "estórias". Lisboa: Vega, 1999.

MORAIS, M. E. S. C. e S. de. Pluralismo e diversidade nos media em Portugal - a blogosfera política em rede. Tese de doutorado. Portugal: Univ. do Minho, 2012.

MOREIRA, S. V. Rádio palanque. Rio de Janeiro: Mil Palavras, 1998.

NEVEU, É. Sociologia do jornalismo. São Paulo: Loyola, 2006.

PEREIRA, F. H. O jornalista sentado e a produção da notícia online no Correio Web. Em Questão, v. $10, \mathrm{n}^{\circ} 1$, p. 2004.

PINTO, M. Fontes jornalísticas: contributos para o mapeamento do campo. Comunicação e Sociedade. Braga: Universidade do Minho, Vol. 14 (1-2), p. 277-294, 2000.

RUTILLI, M. Rotinas produtivas e relação com as fontes no rádio informativo em ambiente de convergência: um estudo de caso de emissoras de Porto Alegre. Dissertação (Mestrado em Comunicação). Santa Maria: Universidade Federal de Santa Maria, 2014.

SANT'ANNA, F. Mídia das fontes: um novo ator no cenário jornalístico brasileiro - um olhar sobre a ação midiática do Senado Federal. Brasília: Senado Federal, Subsecretaria de Edições Técnicas, 2009.

SCHLESINGER, P. Repenser la sociologie du journalisme: les stratégies de la source d'information et les limites du médiacentrisme. Paris: Réseaux 51, 75-98, 1992.

SCHIMITZ, A. A. Fontes de notícias: ações e estratégias das fontes no jornalismo. Florianópolis: Combook, 2011.

THOMPSON, J. B. Ideologia e cultura moderna: teoria social crítica na era dos meios de comunicação de massa. Petrópolis: Vozes, 2000. 
TUCHMAN, G. La produción de la noticia: estúdio sobre la construción de la realidad. Barcelona: Gili, 1983.

VAN CUILENBURG, J. On Competition, Access and Diversity in Media, Old and New: Some Remarks for Communications Policy in the Information Age. New Media \& Society, v. 1, 1999.

WOLF, M. Teorias da comunicação. Lisboa: Presença, 2009. 